\title{
Assessing Environmental Sustainability of Remediation Technologies in a Life Cycle Perspective is Not So Easy
}

Owsianiak, Mikolaj; Lemming, Gitte; Hauschild, Michael Zwicky; Bjerg, Poul Løgstrup

Published in:

Environmental Science \& Technology (Washington)

Link to article, DOI:

$10.1021 / \mathrm{es} 305279 \mathrm{t}$

Publication date:

2013

Link back to DTU Orbit

Citation (APA):

Owsianiak, M., Lemming, G., Hauschild, M. Z., \& Bjerg, P. L. (2013). Assessing Environmental Sustainability of Remediation Technologies in a Life Cycle Perspective is Not So Easy. Environmental Science \& Technology (Washington), 47(3), 1182-1183. https://doi.org/10.1021/es305279t

\section{General rights}

Copyright and moral rights for the publications made accessible in the public portal are retained by the authors and/or other copyright owners and it is a condition of accessing publications that users recognise and abide by the legal requirements associated with these rights.

- Users may download and print one copy of any publication from the public portal for the purpose of private study or research.

- You may not further distribute the material or use it for any profit-making activity or commercial gain

- You may freely distribute the URL identifying the publication in the public portal 


\title{
Assessing Environmental Sustainability of Remediation Technologies in a Life Cycle Perspective is Not So Easy
}

\author{
Mikołaj Owsianiak, ${ }^{* 1}$ Gitte Lemming, ${ }^{2}$ Michael Z. Hauschild, ${ }^{1}$ and Poul L. Bjerg ${ }^{2}$ \\ ${ }^{1}$ Division for Quantitative Sustainability Assessment, Department of Management Engineering, \\ Technical University of Denmark, Nils Koppels Alle, Building 426D, DK-2800 Kgs. Lyngby, \\ Denmark
}

${ }^{2}$ Department of Environmental Engineering, Technical University of Denmark, Miljoevej, Building 113, DK-2800 Kgs. Lyngby, Denmark

Integrating sustainability into remediation projects has attracted attention from remediation practitioners, and life cycle assessment (LCA) is becoming a popular tool to address the environmental dimension. The total number of studies has reached 31 since the first framework for LCA of site remediation was published in $1999,{ }^{1}$ and has almost doubled compared to number of studies in two reviews published in 2010. ${ }^{2,3}$ However, our analysis shows an increasing frequency of examples with serious methodological problems (compared to requirements in ISO standards or authoritative guidelines). Figure 1 shows that numerous studies have no or an incomplete definition of the functional unit, omit an appropriate quantification of primary impacts, or fail to include all relevant secondary impact categories. We will illustrate how ignoring these methodological challenges can lead to a misleading conclusion about the environmental sustainability of remediation technologies.

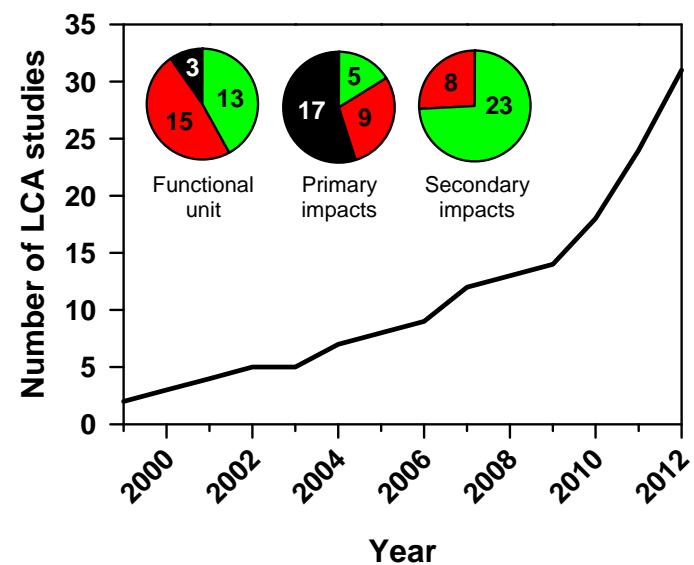

Fig. 1. Cumulative number of published studies on LCA applied to remediation technologies. In the pie charts: Published studies with no methodological problems (green); functional unit incomplete, primary impacts quantified using inappropriate models, or some important secondary impact categories not included (red); functional unit not defined, or primary impacts not quantified (black).

\section{Methodological Challenges}

Definition of the Functional Unit. Defining the functional unit to compare remediation alternatives requires consideration of two interrelated performance parameters, namely the efficiency and time frame for remediation. These parameters have direct influence on the magnitude of primary impacts, i.e. local impacts associated with a contaminated site. If the functional unit 
includes a quantitative indicator of remediation performance, such as reduction of contaminant concentration to the level posing no risk, it should be kept in mind that even a small difference in remediation efficiency between two techniques that both satisfy the no risk level criterion can cause a difference in primary impacts that may influence the comparison. This aspect is particularly important when the difference in remediation time frames between two alternatives is large.

Quantification of Primary Impacts. It is a common practice to quantify primary impacts using generic fate and exposure models. However, these models are based on an average situation and are sufficient to rank chemicals according to their toxicity potential for application in life cycle impact assessment (LCIA), but are not suitable for assessment of toxic impacts at contaminated sites. Conditions at such sites can be far from average because of, e.g., site- and contaminant-specific mass transfer mechanisms in complex porous matrices, or occurrence of toxic biotransformation products. In addition, generic models do not include deep soil and groundwater compartments that are relevant for many contaminants.

Quantification of Secondary Impacts and Comparison with No Action Scenario. Assessing environmental sustainability requires that in addition to primary impacts, all relevant secondary life cycle impacts, i.e. upstream and downstream impacts associated with remediation activities, are quantified. To avoid the risk of environmental problem shifting caused by single-indicator assessments that ignore potential increases in other impacts, ${ }^{4}$ it is not advisable to terminate an LCA at the inventory phase, or include only one or few selected impact categories for assessment of secondary impacts. In addition, quantifying all relevant life cycle impacts is a prerequisite for a bias-free comparison with a no action scenario to determine whether there is a net environmental benefit from remediation. This requires considerations of relative weight between primary and secondary impacts.

\section{Example of Trichloroethene Remediation}

Lack of consideration of the aforementioned aspects can lead a misleading conclusion about environmental sustainability of remediation. To illustrate with an example, consider a site contaminated by the dense non-aqueous phase liquid (DNAPL), trichloroethene (TCE). Because enhanced reductive dechlorination (ERD) is less efficient than thermal remediation in removing TCE mass, primary impacts from human exposure to TCE through contaminated groundwater will be more severe if the former is chosen as remediation strategy. Even assuming the same remediation efficiency of the two alternatives in the long-term, the primary impacts from ERD will still be higher because the time frame for ERD is longer.

The generic steady state characterization model USEtox (www.usetox.org) predicts that $85 \%$ of TCE emitted to soil will be found in the air, where it degrades quickly. In reality, the major problem for this, and other DNAPLs, is the long-term contamination of deep soil and groundwater. Formation of toxic vinyl chloride, a metabolite of anaerobic biodegradation of TCE, further highlights the need for using site specific models to allow for robust quantification of primary impacts. Apart from metal contaminations (where the generic characterization models are recognized to overestimate the toxicity potential), primary impacts are usually underestimated in LCAs. Primary impacts are particularly important if their contribution to total environmental impacts is large, which can be the case of some less invasive remediation techniques.

Ignoring the trade-offs between primary impacts and secondary impacts leads to a paradox situation from a site management perspective because it is the local problem that is usually a driver 
for action. Assuming equal weight of primary and secondary impacts, Lemming et al. ${ }^{5}$ demonstrated how four different management options for a TCE-contaminated site (including the long-term monitoring combined with treatment of contaminated groundwater at waterworks) can lead to higher impacts than those avoided through remediation. This study also illustrated the relevance of including all life cycle impact categories to avoid problem shifting; a change in oxidizing agent for in situ remediation can reduce impact on global warming, but can increase other life cycle impacts.

\section{Implications for Life Cycle Assessment}

In order to avoid sub-optimization in assessment of remedial options we recommend that LCA practitioners define a functional unit that includes remediation efficiency, and subsequently determine time frames for each option. Alternatively, a functional unit can include time frame for remediation and then option-specific efficiencies can be determined. Furthermore, we recommend using site specific models to quantify primary impacts and including all life cycle impact categories in assessment of secondary impacts. We eventually advocate including a no action scenario as a reference point to which any remediation option should be compared. The increasing interest in applying LCA to support decision makers in contaminated site management will hopefully direct us towards greener solutions. A limited number of studies without serious methodological problems and only occasional comparisons with no action scenario suggest however, that even in relative terms no technology for cleaning up contaminated soil or groundwater can yet be claimed green or environmentally sustainable.

\section{Author Information}

\section{Corresponding Author}

*E-mail: miow@dtu.dk.

\section{References}

(1) Diamond, M.L.; Page, C.A.; Campbell, M.; McKenna, S.; Lall, R. Life-cycle framework for assessment of site remediation options: method and generic survey. Environ. Toxicol. Chem. 1999, $18,788-800$.

(2) Morais, S.A.; Delerue-Matos, C. A perspective on LCA application in site remediation services: critical review of challenges. J. Hazard. Mater. 2010, 175, 12-22.

(3) Lemming, G.; Hauschild, M.Z.; Bjerg, P.L. Life cycle assessment of soil and groundwater remediation technologies: literature review. Int. J. Life Cycle Assess. 2010, 15, 115-127.

(4) Laurent, A.; Olsen, S.I.; Hauschild, M.Z. Limitations of carbon footprint as indicator of environmental sustainability. Environ. Sci. Technol. 2012, 46, 4100-4108. 
(5) Lemming, G.; Chambon, J.C.; Binning, P.J.; Bjerg, P.L. Is there an environmental benefit from remediation of a contaminated site? Combined assessments of the risk reduction and life cycle impact of remediation. J. Environ. Manage. 2012, 112, 392-403. 